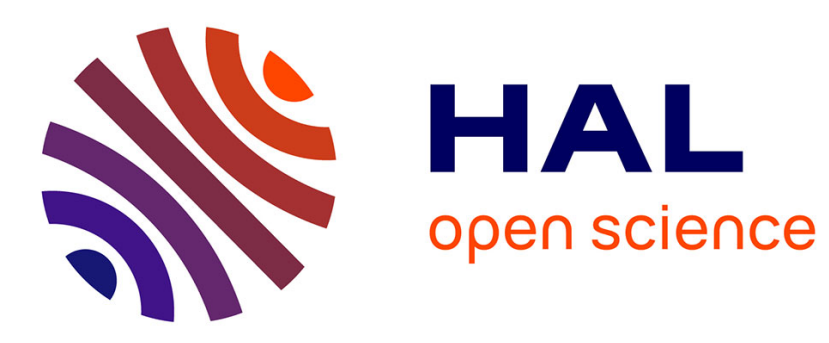

\title{
Kinetic Modelling of High Density PolyEthylene Pyrolysis: Part 2. Reduction of existing detailed mechanism
}

Nicolas Gascoin, Ana Navarro-Rodriguez, Guillaume Fau, Philippe Gillard

\section{- To cite this version:}

Nicolas Gascoin, Ana Navarro-Rodriguez, Guillaume Fau, Philippe Gillard. Kinetic Modelling of High Density PolyEthylene Pyrolysis: Part 2. Reduction of existing detailed mechanism. Polymer Degradation and Stability, 2012, 97, pp.1142-1150. 10.1016/j.polymdegradstab.2012.04.002 . hal00705544

\section{HAL Id: hal-00705544 https://hal.science/hal-00705544}

Submitted on 11 Jun 2012

HAL is a multi-disciplinary open access archive for the deposit and dissemination of scientific research documents, whether they are published or not. The documents may come from teaching and research institutions in France or abroad, or from public or private research centers.
L'archive ouverte pluridisciplinaire HAL, est destinée au dépôt et à la diffusion de documents scientifiques de niveau recherche, publiés ou non, émanant des établissements d'enseignement et de recherche français ou étrangers, des laboratoires publics ou privés. 


\section{Accepted Manuscript}

Kinetic modelling of high density polyethylene pyrolysis: Part 2. Reduction of existing detailed mechanism

N. Gascoin, A. Navarro-Rodriguez, G. Fau, P.Gillard

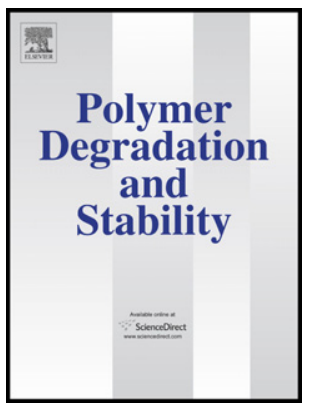

PII:

S0141-3910(12)00140-1

DOI:

10.1016/j.polymdegradstab.2012.04.002

Reference: $\quad$ PDST 6634

To appear in: Polymer Degradation and Stability

Received Date: 31 January 2012

Revised Date: 21 March 2012

Accepted Date: 10 April 2012

Please cite this article as: Gascoin N, Navarro-Rodriguez A, Fau G, P.Gillard, Kinetic modelling of high density polyethylene pyrolysis: Part 2. Reduction of existing detailed mechanism, Polymer Degradation and Stability (2012), doi: 10.1016/j.polymdegradstab.2012.04.002.

This is a PDF file of an unedited manuscript that has been accepted for publication. As a service to our customers we are providing this early version of the manuscript. The manuscript will undergo copyediting, typesetting, and review of the resulting proof before it is published in its final form. Please note that during the production process errors may be discovered which could affect the content, and all legal disclaimers that apply to the journal pertain. 


\title{
Kinetic Modelling of High Density PolyEthylene Pyrolysis: Part 2. Reduction of existing detailed mechanism.
}

\author{
N. Gascoin ${ }^{1}$, A. Navarro-Rodriguez ${ }^{2}$, G. Fau ${ }^{3}$, P.Gillard ${ }^{4}$ \\ University of Orléans, 63 avenue de Lattre de Tassigny, 18020 Bourges, France
}

\begin{abstract}
Nowadays, a great effort in hybrid rocket technology is being made in order to develop Computational Fluid Dynamics (CFD) models to investigate the coupled fuel pyrolysis and by-products combustion phenomena. Detailed chemistry must be considered to determine with accuracy the chemical induction delays which play a major role on the stability of the system. A highly detailed High Density PolyEthylene (HDPE) pyrolysis mechanism has been selected (7541 reactions and 1014 species) to be reduced. A new mechanism is created and validated over a temperature range from $700 \mathrm{~K}$ to $1200 \mathrm{~K}$ and for pressure from 1 bar to 100 bar. Two methods have been successively applied (Detailed Reduction and Direct Relation Graph with and without Error Propagation). Several sets of species have been defined to ensure the validity and the appropriateness of this mechanism with another existing detailed one for combustion. The final mechanism (1713 reactions and 472 species) is demonstrated to be the optimal one, according to the validation criteria (accuracy of 5 mol.\% on HDPE consumption and on $\mathrm{C}_{2} \mathrm{H}_{4}$ formation). The computation cost is reduced by one order of magnitude. This kinetic scheme is successfully implemented in a two dimensions CFD code. Its accuracy is determined quantitatively on the species content under steady-state and transient conditions. The reduction work allows quantifying the importance of $\beta$-scission reactions compared to backbiting and random scission reactions while dienes, alkanes and alkenyl radicals have been mostly removed due to their limited impact.
\end{abstract}

Keywords: Polyethylene; pyrolysis; kinetic mechanism; chemistry reduction; hybrid propulsion.

\footnotetext{
${ }^{1}$ Corresponding author : Nicolas.Gascoin@bourges.univ-orleans.fr, Associate Professor, Tel.: +33 248238 473; Fax: +33 248238 471, 63 avenue de Lattre de Tassigny, 18020 Bourges Cedex FRANCE

${ }^{2}$ Research Engineer

${ }^{3}$ Research Engineer

${ }^{4}$ Full Professor
} 


\section{Introduction}

P olymer pyrolysis is of particular interest for recycling purpose [1] and for propulsion applications [2]. Among the possible polymer able to be used as fuel in hybrid rocket engine, the High Density PolyEthylene (HDPE) is one of the candidates for safety, cost and simplicity reasons [3]. Hybrid motors are made of an oxidiser tank connected by a valve to a solid fuel tank in which the combustion is achieved [2],[4]. The resulting heat flux enables the HDPE pyrolysis to get gaseous combustible. This is a coupled system which deserves to be studied numerically to investigate in details the way the fuel is pyrolysed to produce the species which diffuse from the solid surface to the gas flow. While experiments from lab scale to full scale with firing conditions do exist [5],[6], numerical modelling often remains limited in terms of chemistry because the fluid mechanics description is favoured [7],[8]. For computation time reason, chemistry is generally taken into account by one-step Arrhenius law [2]. Only rare CFD codes consider few steps mechanism [9]. Physically in the engine, a diffusion flame is established in the dynamic boundary layer. The pyrolysis induction delay determines the produced quantity of gas fuel and the autoignition delay -depending on the composition of pyrolysis products- impacts the 2-D position of the diffusion flame. As a consequence, the thrust of the engine is clearly related to the chemistry which needs to be investigated with detailed kinetic mechanism.

Considering HDPE, no detailed pyrolysis mechanism exist in open literature for hybrid rocket use, which consist in temperature over $1000 \mathrm{~K}$, residence time lower than $1 \mathrm{~s}$ and heating rates from $10^{3} \mathrm{~K} \cdot \mathrm{s}^{-1}$ to $10^{6} \mathrm{~K} \cdot \mathrm{s}^{-1}$ [3]. HDPE pyrolysis has been mainly studied for recycling purpose (temperature less than $850 \mathrm{~K}$, residence time much over $1 \mathrm{~s}$ and low heating rates, less than $\left.10^{3} \mathrm{~K} \cdot \mathrm{s}^{-1}\right)[1],[10],[11]$. Some simplified schemes exist without description of the gas phase composition [1],[12]. Two detailed mechanism (Nemeth et al. [10] and Levine and Broadbelt [11]) can be found but the second mechanism is not available to be used neither in a CFD code nor under specific software such as Chemkin. The kinetic mechanism proposed by Nemeth et al. is the only one to the author knowledge to be able computing the gas phase composition. Its validity has been investigated in a companion paper [13] and some limits have been found in case of 0-D computations (related to the computation of the density). Its behaviour is intermediate between the experimental data used to test it, which are not all in agreement due to differences on the HDPE nature and operating conditions. For these reasons, the Nemeth et al. mechanism is used in the present work. Nevertheless, its size is much too high to be implemented in a CFD code. The combustion mechanism of Dagaut and Cathonnet [14] is used in the current CFD code dedicated to the hybrid studies [4]. Its size (1592 reactions and 207 
species) is a reference because it can be handled by the in-house code without computation cost problems. As a consequence, it is expected in the present work to conduct a reduction of the Nemeth et al.' mechanism in order to reach a size lower than 2000 reactions and, if possible, with less than 300 species. Accuracy criteria must be considered to ensure the validity of the mechanism to be proposed. For species mole fractions higher than 50 mol.\%, a disagreement of $10 \%$ is allowed, which means at 80 mol. $\%$ for example, mole fractions of 88 mol. $\%$ or 72 mol.\% are acceptable. For species mole fractions lower than $5 \mathrm{~mol} . \%$, a disagreement of $5 \mathrm{~mol} . \%$ is acceptable, which means at $40 \mathrm{~mol} \%$ for example, mole fractions of $35 \mathrm{~mol} . \%$ or $45 \mathrm{~mol} \%$ are acceptable. These errors are quite coarse but the expected gain on the chemistry prediction is strong enough compared to one step Arrhenius law for example to accept these disagreements. Using such a reduced mechanism would be considered as a major step in hybrid propulsion modelling, despite for purely chemical work it can be seen as coarse approximation.

\section{Preparation of the reduction work}

Several reactions occur in HDPE pyrolysis (random chain scission, $\mathrm{H}$-asbtraction, $\beta$-scission,...) [15]. Numerous solid, liquid and gaseous species are involved in the reaction set (alkanes, alkenes, dienes, radicals, cyclic, aromatic, Polycyclic Aromatic Hydrocarbons) with molecular weight from the one of hydrogen to the one of initial polyethylene (over $125000 \mathrm{~g} \cdot \mathrm{mol}^{-1}$ ) [16]. This complexity explains the difficulty to propose a mechanism, able to predict the formation of products and even their consumption (primary and secondary reaction schemes). As a consequence, the size of the mechanisms increases highly if a fine chemical approach is necessary. The reduction of the scheme is then as difficult as the original generation of the mechanism.

\subsection{Existing reduction methods}

The detailed kinetic mechanisms can be automatically generated through software like Exgas [17] or others [18][20]. The thousand of species and reactions which are considered should then be removed manually or semiautomatically by determining the most important ones to accurately describe the chemical process. As a consequence, numerous methods exist to reduce the size of such highly detailed schemes [21]-[23] and some automated software can be found [24],[25]. The most common methods are based on redundancy theory. Some elimination criteria are defined and the species or the reactions which are not compatible with these criteria are deleted from the mechanism. The reduction methods can be applied complementarily to improve their efficiency. 
The most widely used reduction methods are the Detailed Reduction (DR) and Direct Relation Graph -with Error Propagation- (DRG/DRGEP) methods [26],[27]. The DR method is the simplest one, based on non relevant reaction elimination. It sorts the reactions by reaction rate or reaction enthalpy and it eliminates the reactions corresponding to reaction rates lower than the fixed threshold. In DRG method (kind of graphical method), a set of important species is selected (fuel, oxidizer, important pollutants, other species of interest) and a threshold value is given for the index ratio (parameter related to the maximal error allowed for mechanism reduction, so lower is its value, less aggressive will be the mechanism reduction). Then, the method maps the coupling of species (graph nodes) and it removes the less important ones by eliminating the weakest edges of the graph [27]. The graph edge thickness indicates the dependence of one species with another one. The defined index ratio fixes the critical edge thickness in order to choose the reactions to be considered in the final reduced mechanism. Following a simple graph search, to be initiated at certain preselected target species, the species which are not reached by the search are considered unimportant and they are removed from the mechanism. The DRGEP method is based on the DRG approach, but it uses different algorithm to minimise the error on mass and atom conservation. Apart from these reduction techniques, there are other ones, developed for specific kinetic problems [28]-[31]. For all of them, the validation criteria must be chosen carefully. They are generally related to a restricted range of temperature and pressure.

\subsection{Methodology of this work}

The work is achieved through several intermediate reduction steps. The methodology is the following:

- A maximum size for the final reduced mechanism has been fixed at 2000 reactions as mentioned above because this is roughly the combustion mechanism of Dagault and Cathonnet [14] which is already used in the CFD code in which the pyrolysis mechanism will be implemented [4].

- The accuracy criteria have been selected. An absolute deviation of $5 \mathrm{~mol} \%$ is admitted if the quantities for the reference species are less than $50 \mathrm{~mol} . \%$. If quantities are over $50 \mathrm{~mol} . \%$, a maximal relative error of 10 mol.\% between both results will be admitted.

- The reference species are the compounds which will be strictly monitored during reduction work. Since it is not possible to validate a reduced mechanism for all the species, only few must be selected. HDPE and ethylene are of first importance and these two compounds will serve in order to determine whether the intermediate reduction is promising or not, before validation. 
- If the mechanisms success in the prediction of the chemistry of these two species, then they are tested over methane, ethane, hexane and heptene. This ensures covering a large molecular weight range for species of interest for later coupling with combustion mechanism. Due to the major production of alkenes, compared to dienes and alkanes, alkenes have been preferred in this first validation step. Methane enables considering species lighter than ethylene.

- For the final validation step, the major pyrolysis products must be considered in addition to HDPE. To determine what these species are, computations were done with original mechanism from $700 \mathrm{~K}$ to $1200 \mathrm{~K}$. A set of 46 major pyrolysis products has been obtained (Table 1). The validation will be done by comparing the results from original and reduced mechanisms. For this purpose, the first five species are presented (Methane, Ethylene, Ethane, Hexene and Heptene). They represent $75 \mathrm{~mol} \%$ of pyrolysis mixture for all the temperature values which are tested at times corresponding to $80 \mathrm{~mol} \%$ of conversion rate.

- It is also necessary to determine the temperature and pressure range to conduct the reduction. It has been demonstrated in companion paper [13] that pressure variation has remarkable effect on HDPE pyrolysis principally for low temperature values. Taken that into account, it is not worthy to consider the pressure variation during the reduction process. Intermediate values within the working conditions are chosen: $1000 \mathrm{~K}$ and $10 \mathrm{bar}$.

- Finally, the validation range is extended to test the mechanism: $700 \mathrm{~K}$ to $1200 \mathrm{~K}$ at 1 bar and 34 bar.

In the present study, the Chemical Workbench software is used to conduct the reduction work [32]. The aim is to obtain a reduced mechanism, able to reproduce the pyrolysis in terms of time constant and products distribution, with a limited size and with satisfying accuracy. In the following section 3.1, the reduction strategy which has finally been selected is presented. It is a result of a large work on the basis of trial-and-error approach to determine the accuracy of the different possible reduction methods. Then, with the same methodology, different set of species are selected to obtain the best accuracy for the species of interest (section 3.2). An analysis of the species and reactions which are removed is provided to analyse the importance of different species groups and reactions types (section 3.3). A validation of the reduced mechanism is proposed (section 3.4) and transient behaviour is analysed (section 3.5) for future CFD applications.

Table 1 should be placed here 


\section{Reduction of Nemeth mechanism}

In this section, the original Németh et al.' nomenclature is respected [10]. P40 stands for HDPE, ANE denotes alkanes, ENE denotes alkenes, DI- for a double bond and R- stands for radicals. The number following ANE or ENE is the number of carbon atoms. Two particular times will be used in this section. The first one, the so-called "critical time", corresponds to a HDPE conversion rate of $80 \mathrm{~mol} \%$. The second one is the so-called "pyrolysis time" which presents 99.99 mol.\% of HDPE pyrolysis rate. Analysing the results at two different times enable a better prediction of transient chemical evolutions.

\subsection{Reduction strategy}

Three reduction techniques have been used: Detailed Reduction method (DR), Direct Graph Relation method (DRG) and Direct Graph Relation method with Error Propagation (DRGEP). The parameters which can be controlled and optimised are the threshold value chosen for DR reduction, the set of species selected for DRG(EP) methods and the order of application of these different reduction techniques.

First of all, the order of application of the different techniques and the size of the set of important species for DRG/DRGEP reduction is analyzed. In Figure 1, the relevance of the order of application of the methods has been tested, for both critical and pyrolysis time. In both reduction cases, same threshold values are adopted.

- DR reduction + DRG reduction: a reduced mechanism with 4347 reactions and 308 species is obtained.

- DRG reduction + DR reduction: a reduced mechanism with 3993 reactions and 307 species is generated.

The second reduction strategy gives a more reduced mechanism. Nevertheless, the disagreement for HDPE can reach about $75 \%$ at critical time (Figure 1a) with this second method and $30 \%$ for the pyrolysis time (Figure $1 \mathrm{~b}$ ) instead of $30 \%$ and $2 \%$ respectively for the first method. As a result, an erroneous estimation of HDPE conducts directly to an approximated estimation of other products as it can be seen on Figure 1 for $\mathrm{CH}_{4}, \mathrm{C}_{2} \mathrm{H}_{4}$ and $\mathrm{C}_{2} \mathrm{H}_{6}$. Consequently, the first reduction strategy is selected in the present work.

\section{Figure 1 should be placed here}

Furthermore, the effect of the threshold value should be investigated. Two possibilities exist.

- Reduction strategy DR A: it consists in a try-and-error method to find an optimal threshold value. The reduction is directly applied onto the original kinetic mechanism. Several mechanisms can be obtained without relationship between each of them. 
- Reduction strategy DR B: reduction is started with a low threshold value which is increased step by step. This second method reduces the mechanism through each increase of the threshold value and this generates several successive intermediate mechanisms.

As an example, a DR reduction with a threshold value of $10^{15} \mathrm{~mol} \cdot \mathrm{l}^{-1} \cdot \mathrm{s}^{-1}$ is done directly on the original kinetic mechanism. For comparison purpose, DR reductions are applied successively with a threshold value of $10^{13}$ mol.1 ${ }^{1} . \mathrm{s}^{-1}$ on the original mechanism, then $10^{14} \mathrm{~mol} \cdot \mathrm{l}^{-1} \cdot \mathrm{s}^{-1}$ to this intermediate pre-reduced mechanism and finally $10^{15}$ mol. $1^{-1} \cdot \mathrm{s}^{-1}$ to get the last reduced scheme. The reductions are made for the same simulation instant. The relative errors are very similar for both reduction strategies (Figure 2). The first reduction strategy (DR A) gives a reduced mechanism with 6478 reactions and 1014 species. The second one (DR B), gives a slightly bigger mechanism with 6484 reactions and 1014 species. The reduction strategy (DR A) is retained for the present work despite the other one could have been used (minor effect).

\section{Figure 2 should be placed here}

\subsection{Final reduction strategy}

For DRG and DRGEP reduction methods, one of the most relevant parameters is the size of the set of important species, which serves to conduct the reduction. This plays a role in the reduced mechanism accuracy and in the mechanism size. If the size of the set is too small (a minimum number of 50 species has been found for the Németh et al.' mechanism), the reduction is too aggressive. If too many reactions are eliminated, the deviation gets off the validation limits. As a consequence, the choice of the set of important species must be studied.

The DR reduction is used with a threshold value of $10^{15} \mathrm{~mol} \cdot \mathrm{l}^{-1} \cdot \mathrm{s}^{-1}$ until the maximum deviation limit is reached. It must be noted that all reactions in which HDPE appears are kept despite their reaction rate should conduct to their elimination. A reduced mechanism with 5858 reactions and 1014 species is obtained, called Reduced Mechanism DR. The DRG(EP) reduction is then applied. Three different main sets have been chosen with respect to the accuracy and size of the reduced mechanism. They are noted : Combustion Set, Reactant Set and Combustible Set (Table 2 to Table 4). The first one contains all the species which appear in Németh et al.' pyrolysis mechanism and in Dagault and Cathonnet' combustion one to ensure the consistency of both kinetic schemes. The second set of species contains all the compounds with which HDPE reacts in the original mechanism. So that, a good prediction of HDPE consumption should be ensured. The last set of chemical species is made of the molecules with less than 10 
carbon atoms which are not in the two previous sets. It aims at reproducing the kinetic of these species since they are identified as being of importance for a future validation step with appropriate experimental data.

Combining these sets and the two DRG and DRGEP reduction techniques, four additional reduced mechanisms have been obtained (Table 5). As it can be observed at $700 \mathrm{~K}$, none of them completely verifies the validation criteria except the Reduced Mechanism DR (Mechanism V). Some are able to reproduce the HDPE consumption and others are into the margin of error allowed for $\mathrm{C}_{2} \mathrm{H}_{4}$ formation. The sizes of these mechanisms remain important. The effect of the sets of species has been quantified. The deviation from original results for HDPE consumption and $\mathrm{C}_{2} \mathrm{H}_{4}$ production have been determined (Figure 3) for three temperatures and for the five reduced mechanisms given in Table 1. Over $1000 \mathrm{~K}$ (Figure $3 \mathrm{~b}$ and c), the mechanisms conform to validation criteria. For $700 \mathrm{~K}$ (Figure 3a), only the Reduced Mechanism DR presents a deviation under 5 mol.\% but its size is still too large. Discrepancies up to $30 \%$ can be found. The mechanism noted (I) is considered as the reduced mechanism having the best ratio size-deviation of results. It is the one used to obtain the final educed mechanism. For this final step, DRGEP reduction with Combustion Set is applied to the intermediate mechanism (I). This new mechanism is called Reduced Final Mechanism. It contains 1713 reactions and 472 species.

Table 2 should be placed here

Table 3 should be placed here

Table 4 should be placed here

Table 5 should be placed here

Figure 3 should be placed here

\subsection{Analysis of the removed species and reactions}

Before validating the mechanism (presented in section 3.4.), an analysis of the species and reactions which have been removed is provided. The Table 6 summarizes them and classes them by groups. The dienes and alkanes groups are clearly the most reduced $\left(91.2 \%\right.$ and $90 \%$ less respectively). The alkanes $\left(\mathrm{C}_{n} \mathrm{H}_{2 n+2}\right)$ have been removed from C5 to C80 (except C10). This is completely understandable since the classic products distribution is a majority of alkenes $\left(\mathrm{C}_{n} \mathrm{H}_{2 \mathrm{n}}\right)$-appearing in chromatograph for example- after a small diene $\left(\mathrm{C}_{n} \mathrm{H}_{2 n-2}\right)$ quantity and just before an even smaller alkane one for each carbon atoms number [15]. Thus, the alkanes play a minor role in the products 
distribution. This is reinforced when the temperature increases (above $700^{\circ} \mathrm{C}$ ), alkanes decrease and dienes increase while alkenes remain the major compounds [33]. Nevertheless, since the formation of pyrolysis products will then be combined with their combustion, light alkanes have been kept. Similarly (Table 6), dienes have been removed from C78 to C9 but the light ones have been kept since they play a role in the ethylene chemistry [34]-[35]. It should be noted that the reduction methodology presented above conducted to remove these species and the authors did not remove them a priori. As a consequence, it can be understand from these results that it is confirmed that these species have a minor impact to characterize the HDPE pyrolysis and ethylene formation. In addition, it has been shown by Wampler and Levy [33] that the distribution of dienes, alkenes and alkanes follows a linear trend regarding the carbon atoms number. Thus, the dienes and alkanes quantity could be estimated directly through the quantity of alkene and of the carbon atoms number (for species > C6).

Numerous alkenyl radicals $\left(\mathrm{C}_{\mathrm{n}} \mathrm{H}_{2 \mathrm{n}-1}\right)$ have been removed (Table 6), generally those presenting a radical position over the seventh carbon atom of the molecule, and consequently the alkenyl radicals over C9. This demonstrates that these radicals can probably be lumped into a single one for each carbon atoms number when the radicals are over the $7^{\text {th }}$ position in the molecule. Finally, rare alkyl radicals $\left(\mathrm{C}_{\mathrm{n}} \mathrm{H}_{2 \mathrm{n}+1}\right)$ have been removed (Table 6).

As a consequence, on the basis of the species which were removed, the reactions of interest to be kept for the HDPE pyrolysis can be detailed (Table 6). The isomerisation reactions (backbiting, that is to say H-shift) have been removed. Cross-combination between radicals to form alkanes have been removed. This corresponds to the possible lumping of radicals. The recombination reactions (alkenyl radicals into dienes) have almost completely been removed because of the low importance of these species. The fact that most of the alkyl radicals were kept after reduction highlights the importance of $\beta$-scission reactions (only $54.6 \%$ less of such reactions). These latest conduct to the formation of alkenes (found in large majority in products distribution). The alkyl radicals are also found to react with the initial HDPE to form other alkanes and alkyl radicals through $\mathrm{H}$-abstraction $(80.5 \%$ less of reactions in the reduced mechanism). Since most of alkanes have been removed, this show that light alkyl radicals form light alkanes and consequently this is the privileged pathway to form heavy alkyl radicals, then heavy alkenes. Most of the random scission reactions have been kept to reproduce the HDPE pyrolysis, which justifies the large amount of alkyl radicals which have been kept in the final reduced mechanism. To the opposite, the low quantity of alkenyl radicals and of dienes in the final mechanism is coupled because the dienes are formed by $\beta$-scission of alkenyl radicals which were obtained by $\mathrm{H}$-abstraction from the alkenes. This last set of reactions explains the presence of 
alkanes in small quantities. Additional details on reactions pathway can be found in [10] to sustain the analysis of the present results.

\section{Table 6 should be placed here}

\subsection{Validation of the final reduced mechanism}

The final reduced mechanism presents a size of 1713 reactions and 472 species. It conforms to the requirements expressed initially (less than 2000 reactions, agreement with the accuracy criteria). In Table 7, the results for HDPE and $\mathrm{C}_{2} \mathrm{H}_{4}$ contents for critical and pyrolysis time are fairly in agreement with the aim of accuracy (5 mol.\%). The deviation is generally lower than 6 mol.\%. The validation at two time steps is a good point for the transient description of chemical process. At $700 \mathrm{~K}$ and $1200 \mathrm{~K}$, the HDPE consumption and $\mathrm{C}_{2} \mathrm{H}_{4}$ production are compared in Figure 4 with the original mechanism. In addition to these good results, a further validation is required for the others species identified in section 2.2. The results at $700 \mathrm{~K}$ and at $1200 \mathrm{~K}$ are shown in Figure 5. The deviation for all the species is lower than $5 \mathrm{~mol} \%$ (0.05 of molar fraction). The reduced mechanism reproduces a slightly faster kinetic for HDPE consumption, particularly at low temperature. Because of that, an overproduction for all the species is found with the reduced kinetic mechanism. At high temperature, the disagreement is lower and the reduced mechanism still over-predicts the pyrolysis products formation except for ethane. The data are found within the accepted deviation limit. It can be seen for heptene at $700 \mathrm{~K}$ (Figure $5 \mathrm{c}$ ) that the reduced mechanism presents 2 steps of formation and then consumption instead of one for the original mechanism. At $1200 \mathrm{~K}$ (Figure 5d), both present a two step mechanism. This is the same for ethane (Figure 5b).

The errors found for the main species under different temperature conditions are shown in Figure 6 for the critical and pyrolysis times. The values are generally lower or close to $5 \mathrm{~mol} \%$, which is acceptable since the accuracy criterion was $5 \mathrm{~mol} . \%$.

Table 7 should be placed here

Figure 4 should be placed here

Figure 5 should be placed here

Figure 6 should be placed here 
Finally, the time deviation is calculated in order to quantify the different dynamics of original and reduced mechanisms. It has been mentioned in section 1 how the chemical induction delays are important for the hybrid motor. Thus, an uncertainty of the HDPE consumption rate for example can also be seen as a time shift. To compute this so-called time deviation, a given conversion rate is search in original and reduced mechanism. The corresponding simulation time is noted for each case and both are compared to determine how it changes as a function of operating conditions. The results are summarized in Figure 7. The reference time in abscissa is the one of the original mechanism and the time difference is computed by subtracting the time obtained with the reduced mechanism to the reference original one. This time discrepancy appears to be linear for HDPE consumption and $\mathrm{C}_{2} \mathrm{H}_{4}$ formation at $700 \mathrm{~K}, 1000 \mathrm{~K}$ and $1200 \mathrm{~K}$. This is satisfying because it means that the time shift between both models directly depends on the time. A correction can be proposed in the CFD code, for example by multiplying the reaction speed by a time-function. This would strongly decrease the uncertainties observed above for all the species. This time-function is species-dependent.

\section{Figure 7 should be placed here}

\subsection{Optimal reduced mechanism and computation cost gain}

On the basis of the main intermediate reduced mechanisms which have been generated during this work, the decreasing content of HDPE at the critical time is observed as a function of the number of reactions to be considered in the mechanism (Figure 8a). Similarly, the ethylene formation is impacted. The corresponding errors, in comparison with the original mechanism, show that an optimum is found around 1700 reactions because the curves cross them for this number of reactions (Figure 8b). The same can be done for the number of species.

Finally, the computational cost has been determined. Under the same simulation conditions, the original Németh et al.' mechanism has been compared to the final reduced mechanism. The same tolerance and time step values have been fixed for both simulations. A reduction of $90 \%$ of the simulation time has been found at $700 \mathrm{~K}$ for example (10 s of computation time with the reduced mechanism instead of $110 \mathrm{~s}$ originally) and even slightly higher at $1200 \mathrm{~K}, 93.18 \%$ of computation cost gain, because $1.5 \mathrm{~s}$ only were necessary with the new mechanism compared to the $22 \mathrm{~s}$ of the original one. This point is important since the purpose was to enable the use of detailed chemistry with CFD code. A reduction by a factor 10 was one of the criteria of the new mechanism to be generated.

Figure 8 should be placed here 


\section{Conclusion}

Chemical kinetics plays a major role in hybrid propulsion because the nature of gas products generated by solid fuel pyrolysis impacts the combustion depending on the auto-ignition delay. The induction delay of pyrolysis is also important and the diffusion of species impacts the flame anchoring, thus the coupled heat and mass transfers. For this reason, CFD modelling requires considering detailed chemistry with limited number of reactions and species to ensure being able to conduct computations within reasonable time. A detailed HDPE pyrolysis mechanism has been selected among others and validated with available data from literature (see companion paper [13]). It has been reduced with DR and DRG(EP) methods in the present work in order to match the size requirements (less than 2000 reactions). The validation criteria ( 5 mol.\% of accuracy) have been fairly respected for the main species (HDPE, $\mathrm{C}_{2} \mathrm{H}_{4}, \mathrm{CH}_{4}, \mathrm{C}_{2} \mathrm{H}_{6}, \mathrm{C}_{6} \mathrm{H}_{12}, \mathrm{C}_{7} \mathrm{H}_{14}$ ) within a temperature range of $700 \mathrm{~K}-1200 \mathrm{~K}$. The reduced mechanism reproduces with slightly faster kinetics the HDPE consumption, which has for consequence an overproduction of the rest of species. A linear time shift is found between original data and new results at $700 \mathrm{~K}$ but not at $1200 \mathrm{~K}$. The mechanism, with 1713 reactions and 472 species, corresponds to a reduction of $77 \%$ of the number of reactions and $53 \%$ of the number of species. It seems to be the optimal kinetic scheme, according to the defined accuracy and validation criteria. It allows reducing the computation cost by a factor 10 and it is now implemented in a CFD code for full coupled studies of a hybrid rocket engine [4]. During the kinetic reduction, the dienes, the alkanes and the alkenyl radicals have been mostly removed while alkenes and alkyl radicals have been kept. Lumping of alkenyl radicals has been proposed and the major importance of $\beta$-scission over $\mathrm{H}$-abstraction has been shown in the production of alkenes. H-abstraction are mostly important in the formation of heavy alkyl radicals when reacting with the initial HDPE. This mechanism will now be improved thanks to experimental data to be obtained with a flash pyrolysis device up to $1600 \mathrm{~K}, 34$ bar and heating rates of $20000 \mathrm{~K} . \mathrm{s}^{-1}$. These data should be more relevant for hybrid rocket conditions than existing data from literature obtained with thermogravimetric apparatus.

\section{Acknowledgements}

The authors would like to acknowledge the Roxel company for its financial support.

\section{References}

[1] R.W.J. Westerhout, J. Waanders, W.P.M. Van Swaaij, Recycling of polyethene and polypropene in a novel bench-scale rotating cone reactor by high-temperature pyrolysis, Ind. Eng. Chem. Res. 37 (6) (1998) $2293-$ 2300 
[2] M. J. Chiaverini and K. K. Kuo, Fundamentals of hybrid rocket combustion and propulsion, Volume 218, Published by the American Institute of Aeronautics and Astronautics, Reston, Virginia

[3] N. Gascoin and P. Gillard, Preliminary pyrolysis and combustion study for the hybrid propulsion, 46th AIAA Joint Propulsion Conference \& Exhibit, 25-28 Jul 2010, Nashville, AIAA-2010-6871.

[4] A. Mangeot, N. Gascoin, P. Gillard, 2-D Transient Numerical Code for Hybrid Rocket Simulations with Detailed Chemistry, 20th AIAA Computational Fluid Dynamics Conference, 27 - 30 June 2011, Honolulu, Hawaii, AIAA-2011-3212

[5] Connell T L., Santi S A., et al., "Experiment and Semi-Empirical Modeling of Lab-Scale Hybrid Rocket Performance", 45th Joint Propulsion Conference, 2-5 August 2009, Denver, Colorado, AIAA 2009-5086

[6] Nagata H, Ito M, Maeda T, Watanabe M, Uematsu T, Totani T, Kudo I, "Development of CAMUI Hybrid Rocket to Create a Market for Small Rocket Experiments", IAC-05- C4.P.21

[7] Antoniou A and Akyuzlu K M., "A Physics Based Comprehensive Mathematical Model to Predict Motor Performance in Hybrid Rocket Propulsion Systems", 41st AIAA/ASME/SAE/ASEE Joint Propulsion Conference \& Exhibit 10 - 13 July 2005, Tucson, Arizona, AIAA 2005-3541

[8] G Gariani, F Maggi, L Galfetti, Simulation Code for Hybrid Rocket Combustion, 46th AIAA/ASME/SAE/ASEE Joint Propulsion Conference \& Exhibit 25 - 28 July 2010, Nashville, TN

[9] Jackson T.L. and Buckmaster J., "Heterogeneous Propellant Combustion", AIAA Journal Vol. 40, No. 6, June 2002

[10] A. Németh, M. Blazso, P. Baranyai, T. Vidoczy, Thermal degradation of polyethylene modelled on tetracontane, J. Anal. Appl. Pyrolysis 81 (2008) 237-242

[11] S. E. Levine and L. J. Broadbelt, Detailed mechanistic modelling of HDPE pyrolisis: Low molecular weight product evolution, Polymer Degradation and Stability 94 (2009) 810-822

[12] S.M. Al-Salem and P. Lettieri, Kinetic study of high density polyethylene (HDPE) pyrolysis, Polymer

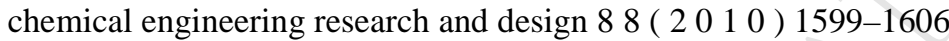

[13] A. Navarro-Rodriguez, N. Gascoin, P.Gillard, A. Mangeot, Kinetic Modelling of High Density PolyEthylene Pyrolysis: Part 1. Comparison of existing models, under submission in Polymer Degradation Journal

[14] P. Dagaut and M. Cathonnet, The ignition, oxidation, and combustion of kerosene: A review of experimental and kinetic modeling, Progress in Energy and Combustion Science, Volume 32, Issue 1, 2006, pp. 48-92.

[15] T. P. Wampler, Applied Pyrolysis Handbook, 2007 Taylor \& Francis Group LLC

[16] J.F. Mastral, C. Berrueco, J. Ceamanos, Modelling of the pyrolysis of high density polyethylene Product distribution in a fluidized bed reactor, J. Anal. Appl. Pyrolysis 79 (2007) 313-322

[17] V Warth, F Battin-Leclerc, R Fournet, P.A Glaude, G.M Come, G Scacchi, Computer based generation of reaction mechanisms for gas-phase oxidation, Computers \& Chemistry, Volume 24, Issue 5, July 2000, pp. 541-560.

[18] A. Németh, T. Vidóczy, K. Héberger, Z. Kúti, and J. Wágner, MECHGEN: Computer Aided Generation and Reduction of Reaction Mechanisms, 2002, J. Chem. Inf. Comput. Sci., 42, 208-214

[19] A. Ratkiewicz and T. N. Truong, Application of Chemical Graph Theory for Automated Mechanism Generation, J. Chem. Inf. Comput. Sci., 43, 36-44

[20] O. Bournez, G. Côme, V. Conraud, H. Kirchner, L. Ibanescu, A Rule-Based Approach for Automated Generation of Kinetic Chemical Mechanisms, 14th International Conference on Rewriting Techniques and Applications - RTA'2003 2706 (2003) 30-45

[21] D. G. VLACHOS, Reduction of detailed kinetic mechanisms for ignition and extinction of premixed hydrogen/air flames, Chemical Engineering Science, Vol. 51, No, 16, pp. 3979-3993, 1996

[22] X. Gou, W. Sun, Z. Chen, Y. Ju, A dynamic multi-timescale method for combustion modeling with detailed and reduced chemical kinetic mechanisms, Combustion and Flame 157 (2010) 1111-1121

[23] A. Mitsos, G.M. Oxberry, P.I. Barton, W.H. Green, Optimal automatic reaction and species elimination in kinetic mechanisms, Combustion and Flame 155 (2008) 118-13

[24] F. Buda, Mecanismes Cinetiques Pour L'amelioration De La Securite Des Procedes D'oxydation Des Hydrocarbures, Thèse de Doctorat, INPL Nancy, Mars 2006

[25] D. Darius, Etude cinétique de la formation des particules de suie à partir de constituants d'un kérosène, Thèse de Doctorat, Université d'Orléans, 2005

[26] T. Lu and C. K. Law, Strategies for mechanism reduction for large hydrocarbons: n-heptane, Combustion and Flame 154 (2008) 153-163

[27] K. E. Niemeyer and C. Sung, DRGEP-based mechanism reduction strategies: graph search algorithms and skeletal primary reference fuel mechanisms, AIAA 2011-508 
[28] J. J. Hernandez, R. Ballesteros, J. Sanz-Argent, Reduction of kinetic mechanisms for fuel oxidation through genetic algorithms, Mathematical and Computer Modelling 52 (2010) 1185_1193

[29] L. Elliott, D. B. Ingham, A. G. Kyne, N. S. Mera, M. Pourkashanian, S. Whittaker, Reaction mechanism reduction and optimisation for modelling aviation fuel oxidation using standard and hybrid genetic algorithms, Computers and Chemical Engineering 30 (2006) 889-900

[30] W. Sun, Z. Chen, X. Gou, Y. Ju, A path flux analysis method for the reduction of detailed chemical kinetic mechanisms, Combustion and Flame 157 (2010) 1298- 1307

[31] K. Heioannis, P.Androulakis, Marianthi G.Ierapetritou, On-the-fly reduction of kinetic mechanisms using element flux analysis, Chemical Engineering Science 65 (2010) 1173-1184

[32] M. Deminsky, V. Chorkov, G. Belov, I. Cheshigin, A. Knizhnik, E. Shulakova, M. Shulakov, I. Iskandarova, V. Alexandrov, A. Petrusev, I. Kirillov, M. Strelkova, S. Umanski, Chemical Workbench-integrated environment for materials science, Computational Materials Science 28 (2003) 169-178

[33] T.P. Wampler, E.J. Levy, Effect of heating rate on oxidative degradation of polymeric materials, Journal of Analytical and Applied Pyrolysis, 8 (1985), 153-161

[34] Y. Hidaka, T. Nishimori, K. Sato, Y. Henmi, R. Okuda, K. Inami, T. Higashihara, Shock-Tube and Modeling Study of Ethylene Pyrolysis and Oxidation, Combustion and Flame 117 (1999), 755-776

[35] T. Faravelli, A. Goldaniga, E. Ranzi, The Kinetic Modeling Of Soot Precursors In Ethylene Flames, TwentySeventh Symposium (International) on Combustion/The Combustion Institute, 1998, pp. 1489-1495 
Figure 1 Relative errors on HDPE and $\mathrm{C}_{2} \mathrm{H}_{4}(\mathrm{a}, \mathrm{c})$ and on $\mathrm{CH}_{4}$ and $\mathrm{C}_{2} \mathrm{H}_{6}(\mathrm{~b}, \mathrm{~d})$ found with two different reduction strategies DR + DRG and DRG + DR for critical time (a, b) and pyrolysis time (c, d).

Figure 2 Relative errors found on HDPE and $\mathrm{C}_{2} \mathrm{H}_{4}$ at critical time with two different strategies : single DR reduction with threshold of $10^{15} \mathrm{~mol} . \mathrm{l}^{-1} . \mathrm{s}^{-1}$ (DR A) and successive DR reductions (DRB B) (thresholds from $10^{13} \mathrm{~mol} . \mathrm{l}^{-1} \cdot \mathrm{s}^{-1}$ to $\left.10^{15} \mathrm{~mol} \cdot \mathrm{l}^{-1} \cdot \mathrm{s}^{-1}\right)$.

Figure 3 Deviation from original results for reduced mechanism I to V on HDPE and $\mathrm{C}_{2} \mathrm{H}_{4}$ content at $700 \mathrm{~K}$ (a), 1000 $\mathrm{K}(\mathrm{b})$ and $1200 \mathrm{~K}(\mathrm{c})$.

Figure 4 Results for HDPE consumption and $\mathrm{C}_{2} \mathrm{H}_{4}$ production at $700 \mathrm{~K}$ (a) and $1200 \mathrm{~K}$ (b) and 1 bar using original mechanism and Final Reduced Mechanism.

Figure 5 Comparison of the final reduced mechanism with the original one for methane (Original - and reduced "*.." ), hexane (Original $\boldsymbol{\sim}$ and Reduced $\boldsymbol{\bullet}$ ), ethane (Original $\boldsymbol{-} \boldsymbol{-}$ and Reduced---), and heptene (Original $\boldsymbol{\bullet} \boldsymbol{\bullet}$ and Reduced ---) production at 1 bar and $700 \mathrm{~K}(\mathrm{a}, \mathrm{c})$ and $1200 \mathrm{~K}(\mathrm{~b}, \mathrm{~d})$

Figure 6 Relative errors between original Németh et al.' mechanism and final reduced mechanism for different temperatures at critical time (a) and pyrolysis time (b).

Figure 7 Time deviation between reduced and original mechanisms for HDPE consumption and $\mathrm{C}_{2} \mathrm{H}_{4}$ production at 1 bar and different temperature conditions.

Figure 8 Effect of the number of reactions in the mechanism on the HDPE consumption and $\mathrm{C}_{2} \mathrm{H}_{4}$ formation at the critical time (a) and corresponding error in comparison with the original mechanism (b) at 1 bar and $700 \mathrm{~K}$.

Table 1 Set of species with a mean mole fraction over 0.0001 mol.\% in decreasing order.

Table 2 Combustion Set

Table 3 Reactant Set

Table 4 Combustible Set

Table 5 Size and general behaviour of different reduced mechanisms.

Table 6. Number of reactions and species removed in the original mechanism.

Table 7 Discrepancies found for HDPE and $\mathrm{C}_{2} \mathrm{H}_{4}$ (in mol.\%) between original and reduced mechanisms for two different times and three temperatures at 1 bar. 

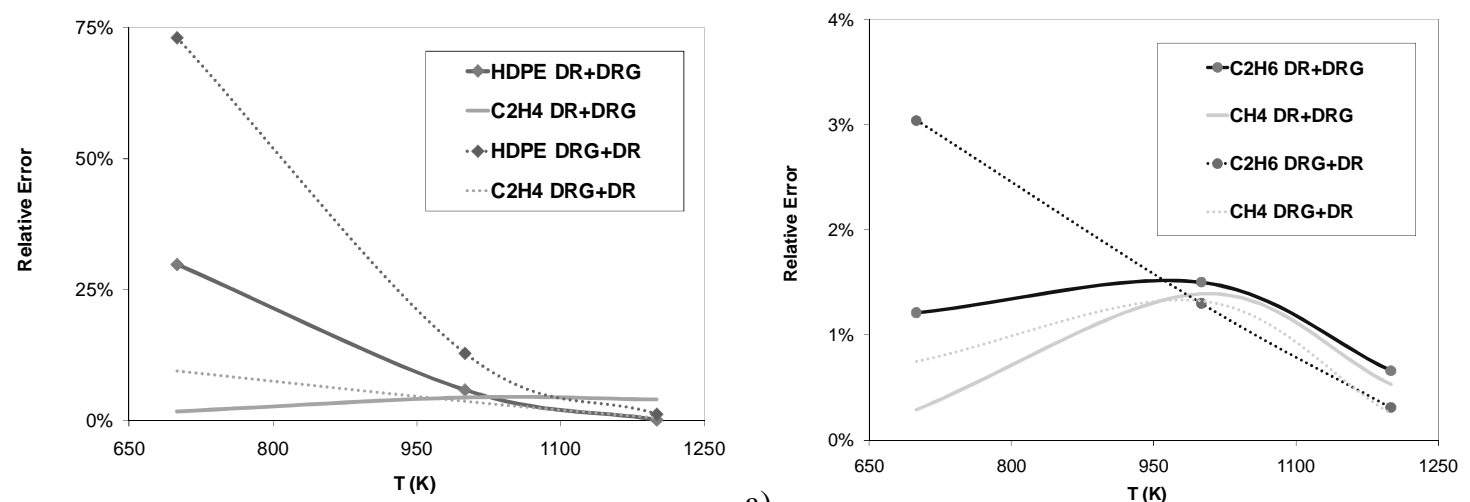

a)

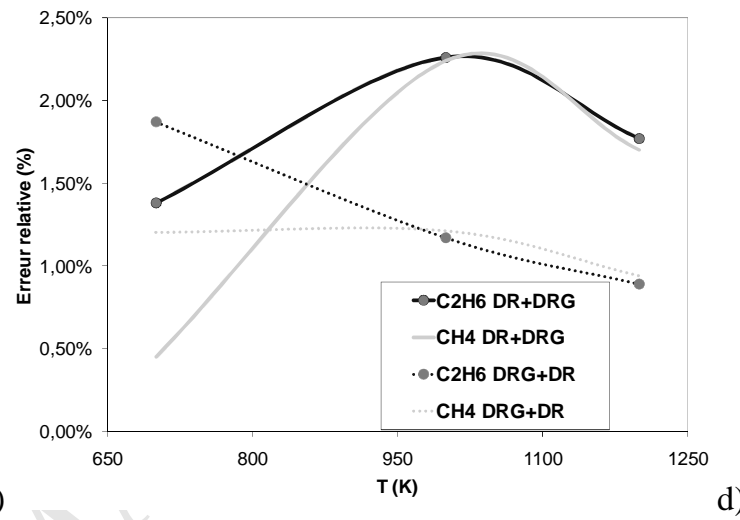

b)

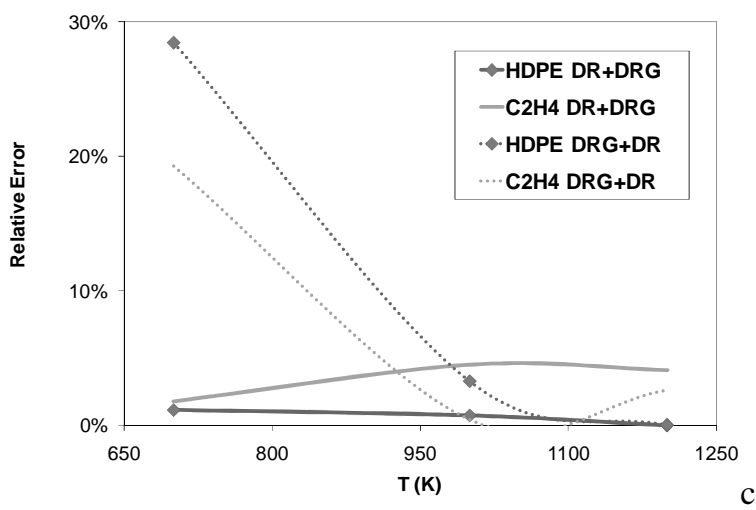

Figure 1 Relative errors on HDPE and $\mathrm{C}_{2} \mathrm{H}_{4}(\mathrm{a}, \mathrm{c})$ and on $\mathrm{CH}_{4}$ and $\mathrm{C}_{2} \mathrm{H}_{6}(\mathrm{~b}, \mathrm{~d})$ found with two different reduction strategies DR + DRG and DRG + DR for critical time (a, b) and pyrolysis time (c, d). 


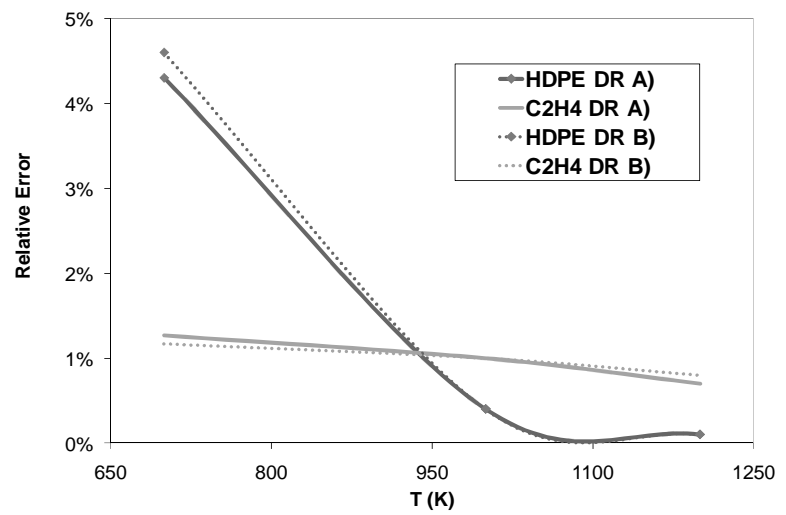

Figure 2 Relative errors found on $\mathrm{HDPE}$ and $\mathrm{C}_{2} \mathrm{H}_{4}$ at critical time with two different strategies : single DR reduction with threshold of $10^{15} \mathrm{mol.l}^{-1} . \mathrm{s}^{-1}$ (DR A) and successive DR reductions (DRB B) (thresholds from $10^{13}$ mol. $\mathrm{I}^{-1} . \mathrm{s}^{-1}$ to $\left.10^{15} \mathrm{mol.}^{-1} . \mathrm{s}^{-1}\right)$. 

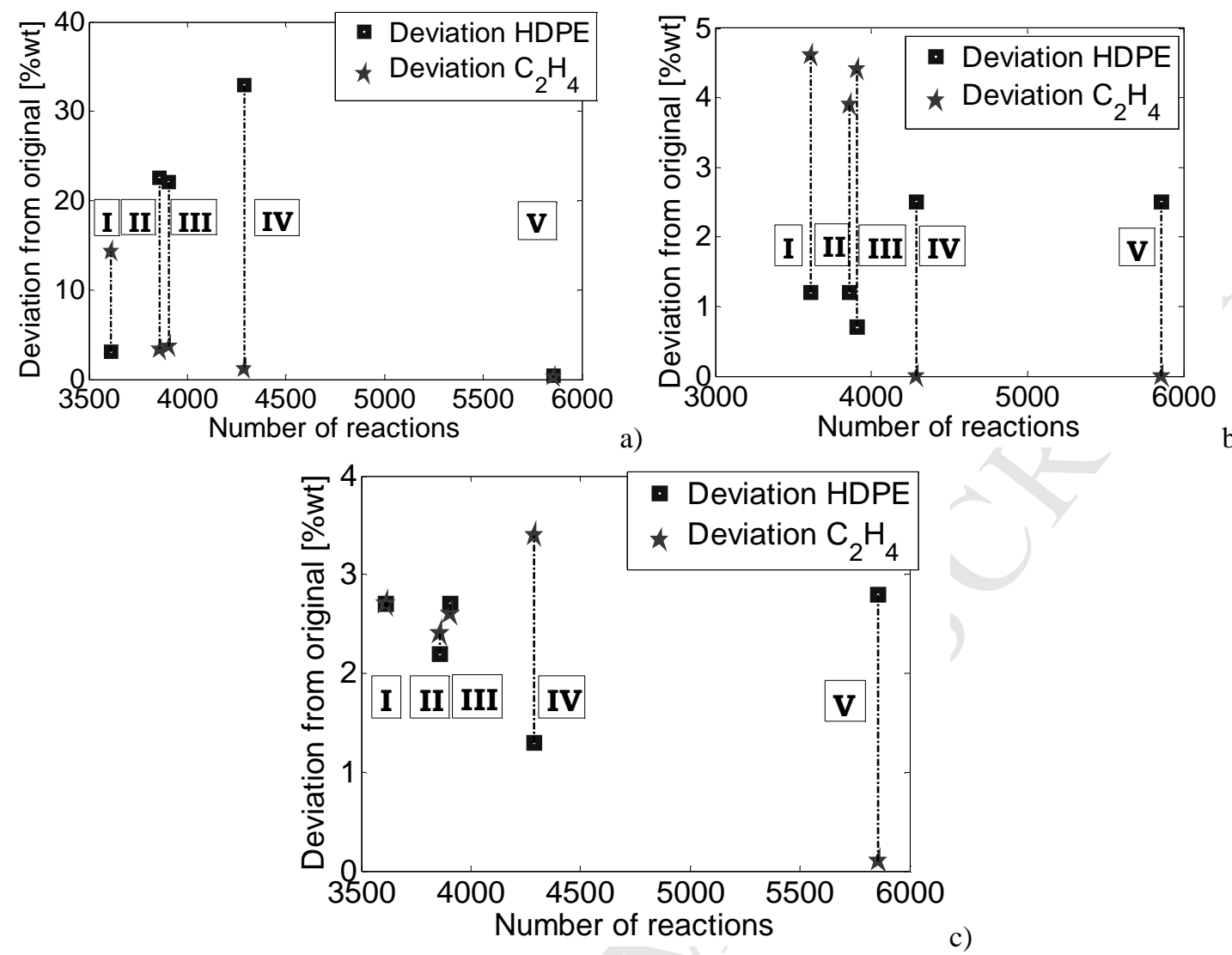

c)

Figure 3 Deviation from original results for reduced mechanism I to $V$ on $\mathrm{HDPE}$ and $\mathrm{C}_{2} \mathrm{H}_{4}$ content at $700 \mathrm{~K}$ (a), $1000 \mathrm{~K}$ (b) and $1200 \mathrm{~K}$ (c). 

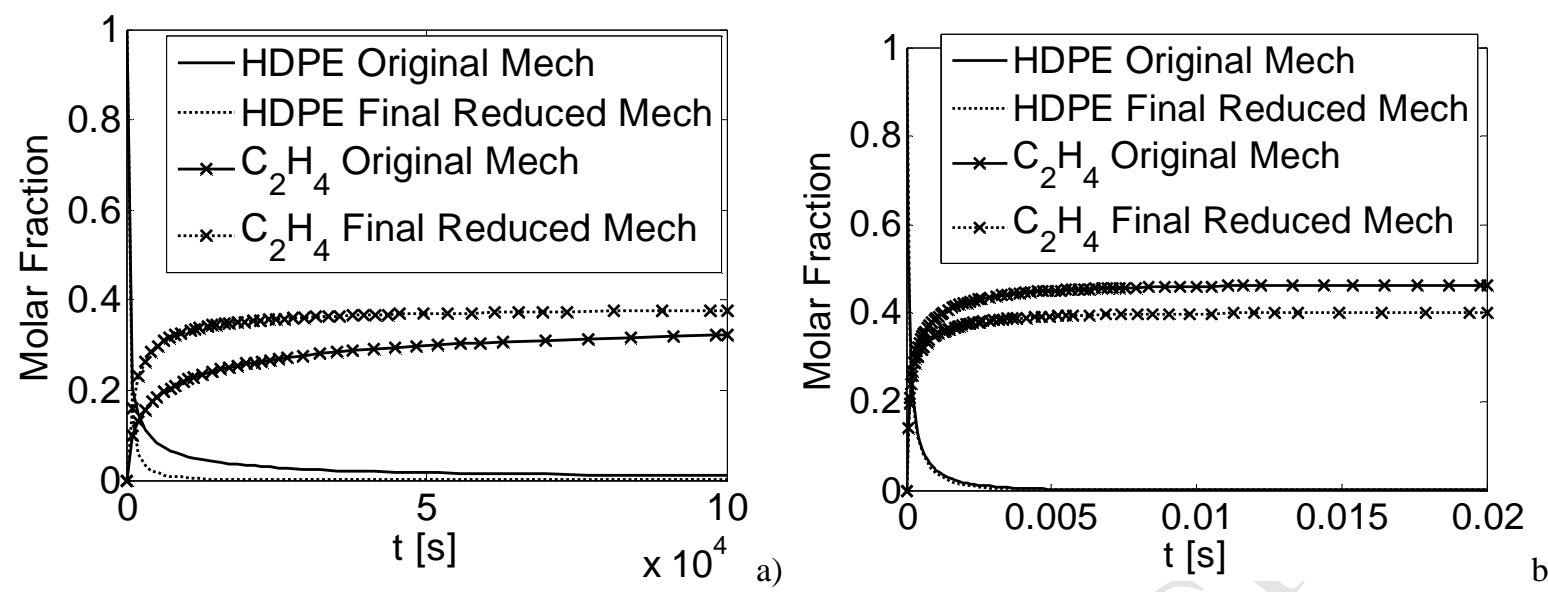

Figure 4 Results for HDPE consumption and $\mathrm{C}_{2} \mathrm{H}_{4}$ production at $700 \mathrm{~K}$ (a) and $1200 \mathrm{~K}$ (b) and 1 bar using original mechanism and Final Reduced Mechanism. 

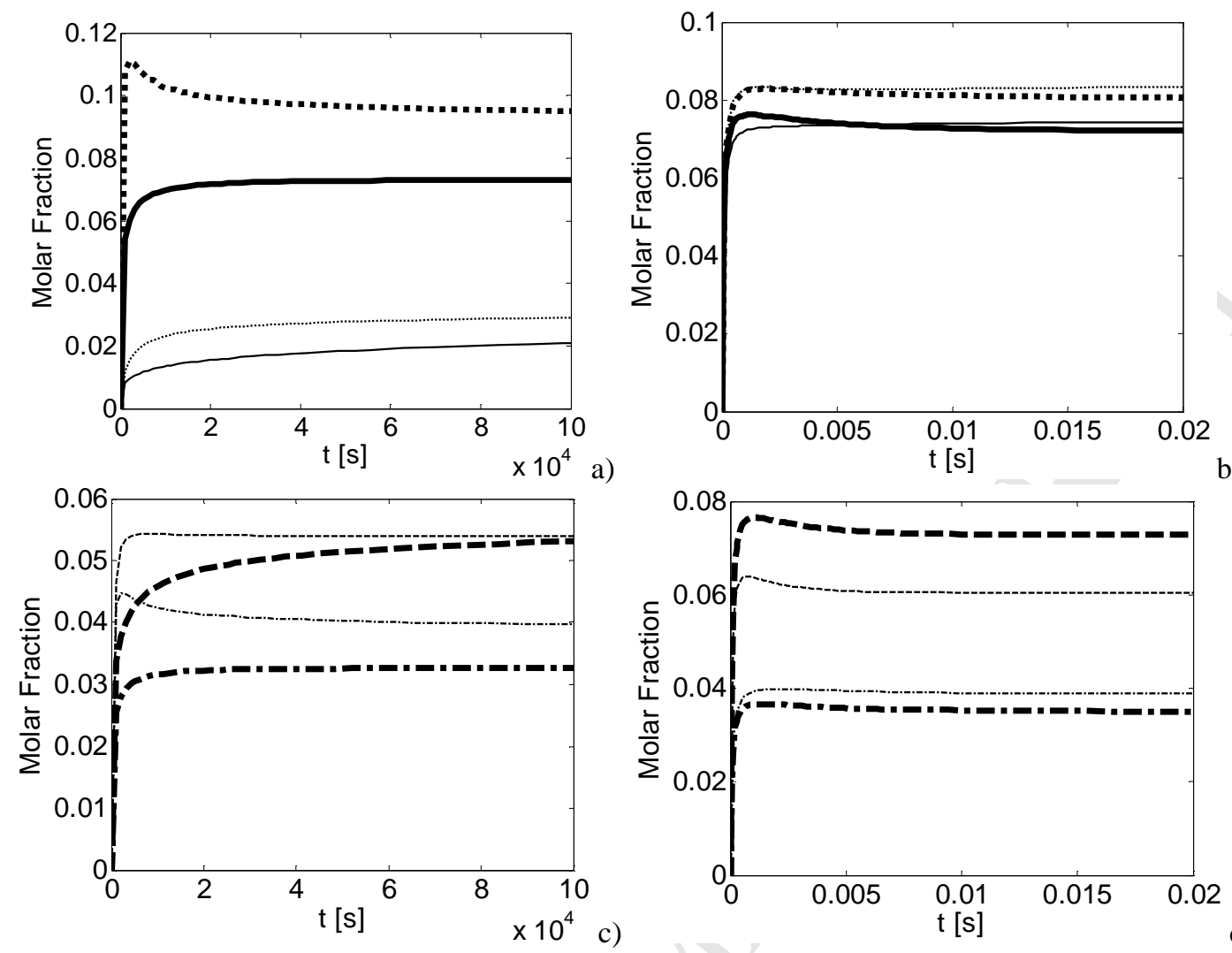

b)

Figure 5 Comparison of the final reduced mechanism with the original one for methane (Original - and reduced "'"."'), hexane (Original $\boldsymbol{C}$ and Reduced " "), ethane (Original $\boldsymbol{-}$ - and Reduced---), and heptene (Original - - and Reduced ---) production at 1 bar and $700 \mathrm{~K}(\mathrm{a}, \mathrm{c})$ and $1200 \mathrm{~K}(\mathrm{~b}, \mathrm{~d})$ 

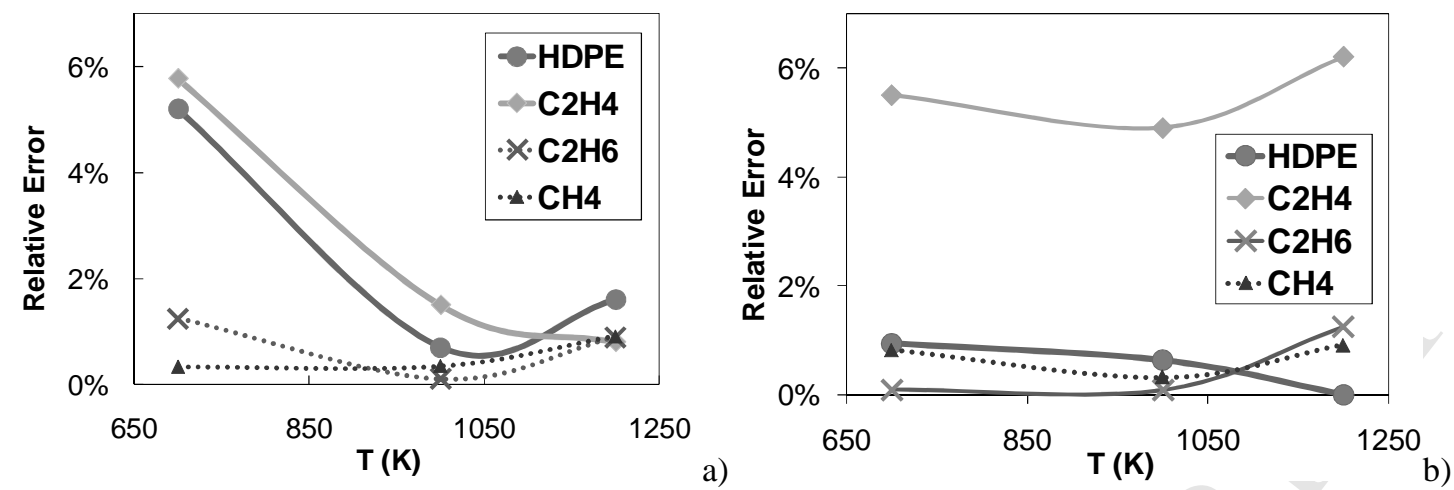

Figure 6 Relative errors between original Németh et al.' mechanism and final reduced mechanism for different temperatures at critical time (a) and pyrolysis time (b). 


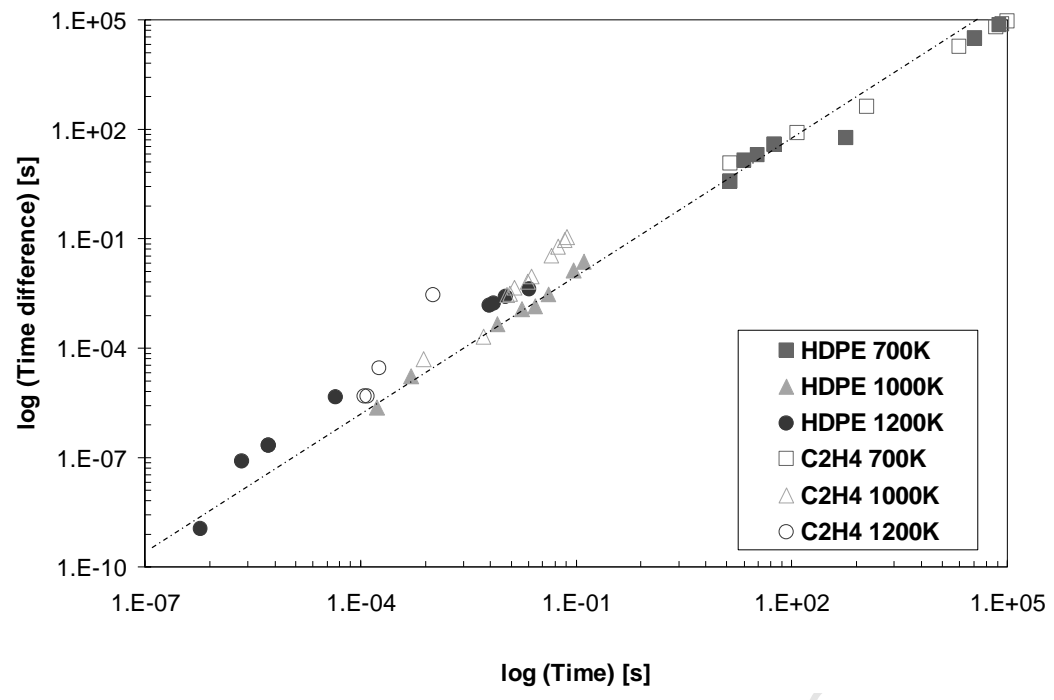

Figure 7. Time deviation between reduced and original mechanisms for HDPE consumption and $\mathrm{C}_{2} \mathrm{H}_{4}$ production at 1 bar and different temperature conditions. 

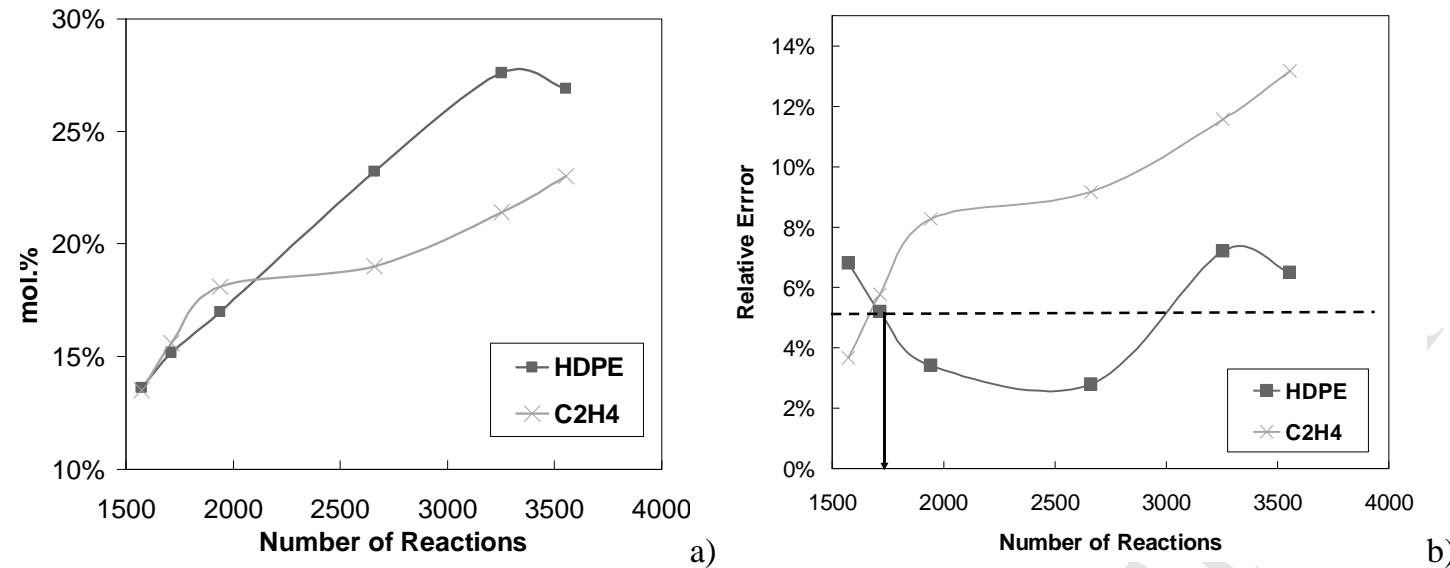

Figure 8. Effect of the number of reactions in the mechanism on the HDPE consumption and $\mathrm{C}_{2} \mathrm{H}_{4}$ formation at the critical time (a) and corresponding error in comparison with the original mechanism (b) at 1 bar and $700 \mathrm{~K}$. 
Table 1 Set of species with a mean mole fraction over 0.0001 mol.\% in decreasing order.

\begin{tabular}{|c||c|}
\hline ENE2 $\left(\mathbf{C}_{\mathbf{2}} \mathbf{H}_{\mathbf{4}}\right)$ & DIENE16 \\
\hline ANE1 $\left(\mathbf{C}_{\mathbf{1}} \mathbf{H}_{\mathbf{4}}\right)$ & DIENE15 \\
\hline ANE2 $\left(\mathbf{C}_{\mathbf{2}} \mathbf{H}_{\mathbf{6}}\right)$ & DIENE14 \\
\hline ENE6 $\left(\mathbf{C}_{\mathbf{6}} \mathbf{H}_{\mathbf{1 2}}\right)$ & DIENE13 \\
\hline ENE7 $\left(\mathbf{C}_{\mathbf{7}} \mathbf{H}_{\mathbf{1 4}}\right)$ & DIENE12 \\
\hline ENE5 & DIENE11 \\
\hline ENE3 & DIENE23 \\
\hline ENE4 & DIENE22 \\
\hline ANE3 & DIENE21 \\
\hline ANE4 & DIENE20 \\
\hline ENE8 & DIENE19 \\
\hline ENE10 & DIENE24 \\
\hline ENE9 & DIENE25 \\
\hline DIENE5 & DIENE26 \\
\hline ENE11 & DIENE27 \\
\hline DIENE6 & DIENE29 \\
\hline DIENE8 & DIENE28 \\
\hline ENE12 & DIENE30 \\
\hline DIENE10 & DIENE31 \\
\hline DIENE9 & DIENE33 \\
\hline DIENE7 & DIENE32 \\
\hline DIENE18 & DIENE35 \\
\hline DIENE17 & DIENE34 \\
\hline
\end{tabular}


Table 2 Combustion Set

\begin{tabular}{|cccccccc|}
\hline C10H22 & R10r1 & R8r5 & R4r1 & RENE10r9 & RENE8r6 & RENE5r4 & C10H20 \\
C4H10 & R10r4 & R8r6 & R3r1 & RENE9r3 & RENE8r7 & RENE3r1 & C9H18 \\
C3H8 & R10r5 & R7r1 & R2r1 & RENE9r4 & RENE7r3 & RENE4r1 & C8H16 \\
C2H6 & R10r6 & R7r4 & R1r1 & RENE9r5 & RENE7r4 & RENE5r1 & C7H14 \\
C1H4 & R9r1 & R7r5 & RENE10r3 & RENE9r6 & RENE7r5 & RENE6r1 & C6H12 \\
C4H6 & R9r4 & R7r6 & RENE10r4 & RENE9r7 & RENE7r6 & RENE7r1 & C5H10 \\
C5H8 & R9r5 & R6r1 & RENE10r5 & RENE9r8 & RENE6r3 & RENE8r1 & C4H8 \\
C6H10 & R9r6 & R6r4 & RENE10r6 & RENE8r3 & RENE6r4 & RENE9r1 & C3H6 \\
C7H12 & R8r1 & R6r5 & RENE10r7 & RENE8r4 & RENE6r5 & RENE10r1 & C2H4 \\
C8H14 & R8r4 & R5r1 & RENE10r8 & RENE8r5 & RENE5r3 & & \\
\hline
\end{tabular}


Table 3. Reactant Set

\begin{tabular}{|lllllllll|}
\hline R39r1 & R37r5 & R34r6 & R30r1 & R27r5 & R24r6 & R20r1 & R17r5 & R14r6 \\
R39r5 & R37r6 & R33r1 & R30r5 & R27r6 & R23r1 & R20r5 & R17r6 & R13r1 \\
R39r6 & R36r1 & R33r5 & R30r6 & R26r1 & R23r5 & R20r6 & R16r1 & R13r5 \\
R38r1 & R36r5 & R33r6 & R29r1 & R26r5 & R23r6 & R19r1 & R16r5 & R13r6 \\
R38r5 & R36r6 & R32r1 & R29r5 & R26r6 & R22r1 & R19r5 & R16r6 & R12r1 \\
R38r6 & R35r1 & R32r5 & R29r6 & R25r1 & R22r5 & R19r6 & R15r1 & R12r5 \\
R37r1 & R35r5 & R32r6 & R28r1 & R25r5 & R22r6 & R18r1 & R15r5 & R12r6 \\
R37r5 & R35r6 & R31r1 & R28r5 & R25r6 & R21r1 & R18r5 & R15r6 & R11r1 \\
R37r6 & R34r1 & R31r5 & R28r6 & R24r1 & R21r5 & R18r6 & R14r1 & R11r5 \\
R37r1 & R34r5 & R31r6 & R27r1 & R24r5 & R21r6 & R17r1 & R14r5 & R11r6 \\
& & & & & & & & R10r1 \\
\hline
\end{tabular}


Table 4. Combustible Set

\begin{tabular}{|lllllllll|}
\hline C9H20 & C8H18 & C7H16 & C6H14 & C5H12 & C4H10 & C3H8 & C9H16 & C10H18 \\
\hline
\end{tabular}


Table 5. Size and general behaviour of different reduced mechanisms.

\begin{tabular}{|c|c|c|c|c|}
\hline $\begin{array}{c}\text { Mechanism } \\
\text { Name }\end{array}$ & $\begin{array}{c}\text { Reduction } \\
\text { Method }\end{array}$ & Set & Final Size & Comments at $700 \mathrm{~K}$ \\
\hline Mechanism I & $\mathrm{DR}+\mathrm{DRG}$ & Combustion Set + Reactant Set & $\begin{array}{c}3612 \text { reactions } \\
897 \text { species }\end{array}$ & $\begin{array}{l}\mathrm{P} 40 \text { consumption } \checkmark \\
\mathrm{C}_{2} \mathrm{H}_{4} \text { production } \times\end{array}$ \\
\hline Mechanism II & DR+DRGEP & Combustion Set + Combustible Set & $\begin{array}{c}3860 \text { reactions } \\
892 \text { species }\end{array}$ & $\begin{array}{l}\mathrm{P} 40 \text { consumption } x \\
\mathrm{C}_{2} \mathrm{H}_{4} \text { production } \checkmark\end{array}$ \\
\hline Mechanism III & $\begin{array}{c}\text { DR+DRG } \\
\text { DR+DRGEP }\end{array}$ & $\begin{array}{c}\text { Combustion Set + Reactant Set } \\
\text { Combustion Set + Combustible } \\
\text { Set }\end{array}$ & $\begin{array}{l}3906 \text { reactions } \\
911 \text { species }\end{array}$ & Validation criterion $x$ \\
\hline Mechanism IV & $\mathrm{DR}+\mathrm{DRG}$ & Combustion Set & $\begin{array}{l}4290 \text { reactions } \\
898 \text { species }\end{array}$ & $\begin{array}{l}\text { P40 consumption } x \\
\mathrm{C}_{2} \mathrm{H}_{4} \text { production } \checkmark\end{array}$ \\
\hline Mechanism V & DR only & No set of species & $\begin{array}{c}5858 \text { reactions } \\
1014 \text { species }\end{array}$ & $\begin{array}{l}\text { P40 consumption } \checkmark \\
\mathrm{C}_{2} \mathrm{H}_{4} \text { production } \checkmark\end{array}$ \\
\hline
\end{tabular}


Table 6. Number of reactions and species removed in the original mechanism.

Species groups /

Reactions types

Alkanes

Alkenes

Dienes

Alkyl radicals

Alkenyl radicals

Random scission

$\beta$-scission

H-abstraction

H-shift (backbiting)-

Isomerisation

Recombination

Cross-combination
Original mechanism

7541 reactions, 1014 species [10]

60

38

57

160

699

20

1529

4997

102

695

198
Reduced mechanism

1713 reactions, 472 species [This work]

$6(-90.0 \%)$

$37(-2.6 \%)$

$5(-91.2 \%)$

$150(-6.3 \%)$

$274(-60.8 \%)$

$18(-10.0 \%)$

$694(-54.6 \%)$

$975(-80.5 \%)$

$21(-79.4 \%)$

$5(-99.3 \%)$

o $(-100.0 \%)$ 
Table 7. Discrepancies found for $\mathrm{HDPE}$ and $\mathrm{C}_{2} \mathrm{H}_{4}$ (in mol.\%) between original and reduced mechanisms for two different times and three temperatures at 1 bar.

\begin{tabular}{|c|c|c|c|}
\hline & \multicolumn{2}{|c|}{ Deviation at } \\
\hline & & critical time & pyrolysis time \\
\hline \multirow{2}{*}{$700 \mathrm{~K}$} & HDPE & $5.20 \%$ & $0.94 \%$ \\
\hline & $\mathrm{C}_{2} \mathrm{H}_{4}$ & $5.77 \%$ & $5.50 \%$ \\
\hline \multirow{2}{*}{$1000 \mathrm{~K}$} & $H D P E$ & $0.70 \%$ & $0.63 \%$ \\
\hline & $\mathrm{C}_{2} \mathrm{H}_{4}$ & $1.50 \%$ & $4.90 \%$ \\
\hline \multirow{2}{*}{$1200 \mathrm{~K}$} & $H D P E$ & $1.60 \%$ & $0.001 \%$ \\
\hline & $\mathrm{C}_{2} \mathrm{H}_{4}$ & $0.80 \%$ & $6.20 \%$ \\
\hline
\end{tabular}

